\title{
Monozygotic twins concordant for congenital short femur
}

\author{
J M CONNOR, P S RAE*, AND R A C CONNOR \\ From the Duncan Guthrie Institute of Medical Genetics, University of Glasgow, Glasgow G3 8SJ.
}

SUMMARY We report concordant male monozygotic twins with congenital short femur (proximal focal femoral deficiency) and discuss the aetiological implications. Coincidentally, they and their father have benign familial macrocephaly.

Congenital short femur (proximal focal femoral deficiency, PFFD) is an uncommon malformation which ranges in severity from mild hypoplasia with shortening and bowing to total absence of the femur. The lesion may be bilateral and in most cases there are other limb malformations, especially absence of the ipsilateral fibula and lateral foot rays (femur-fibula or femur-fibula-ulna complex). Rogala $e t$ al $^{1}$ found an incidence of congenital short femur of 1 in 52029 in Edinburgh and there have now been more than 350 cases reported, mostly in orthopaedic publications. Familial recurrence, however, appears to be exceptional ${ }^{2-4}$ and thus we wish to report concordant monozygotic twins.

\section{Case report}

These male twins were the result of the first pregnancy for a non-consanguineous, normal Scots couple who had no family history of skeletal abnormalities. The father was 45 years and the mother was 38 years old at the time of delivery. The pregnancy had been uneventful and no medications or alcohol had been taken. Delivery was by elective Caesarian section at 39 weeks in view of suspected cephalopelvic disproportion. Birth weights were 3 $\mathrm{kg}$ (twin 1) and $2.8 \mathrm{~kg}$ (twin 2). Histological examination revealed a diamniotic monochorionic placenta, thus confirming monozygosity.

At 1 year of age shortening of the right leg in twin 1 was noted and a radiograph showed shortening of the right femur with angulation at the midpoint and

\footnotetext{
*Present address: Department of Orthopaedic Surgery, Ayr County Hospital, Ayr.

Received for publication 17 April 1985

Revised version accepted for publication 14 August 1985.
}

coxa vara (fig 1). Twin 2 was considered normal at this stage but no radiograph was performed. Examination of twin 1 at 17 months of age revealed a standing height of $77 \mathrm{~cm}$ (10th centile) with $5.5 \mathrm{~cm}$ of true shortening of the right leg. Abduction of the right hip was limited but other movements were normal. Examination of twin 2 at this time revealed a standing height of $80 \mathrm{~cm}$ (25th centile) with $2 \mathrm{~cm}$ of true shortening of the right leg. Joint mobility was normal but a radiograph showed shortening of the right femur and coxa vara (fig 2). Both twins were otherwise normal except for macrocephaly (twin 1 OFC $52.5 \mathrm{~cm}$ at 17 months, twin 2 OFC $55 \mathrm{~cm}$ at 17 months), which was believed to be due to benign familial macrocephaly in view of the father's head

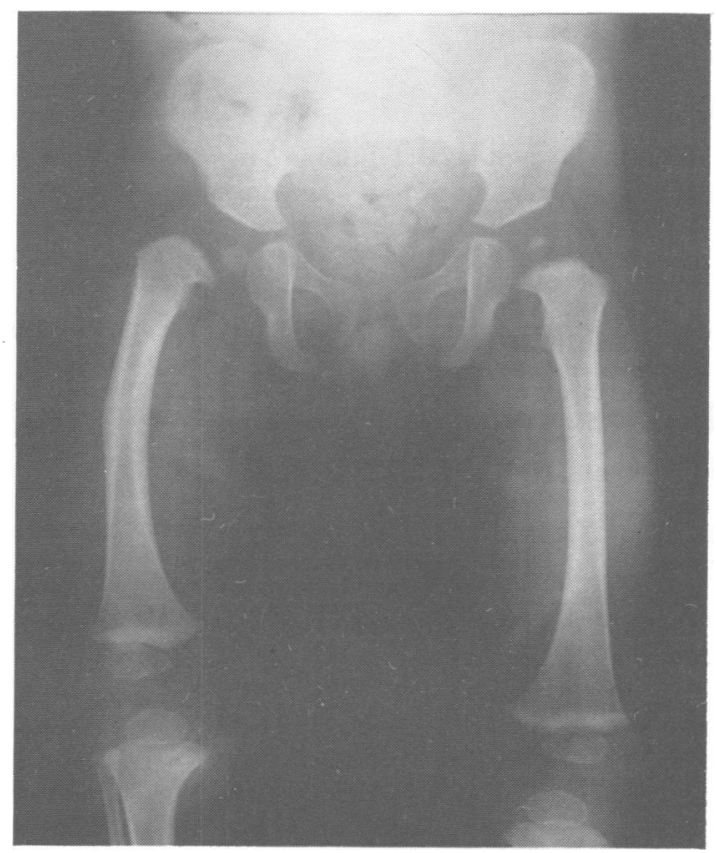

FIG 1 Twin 1 aged 1 year. 


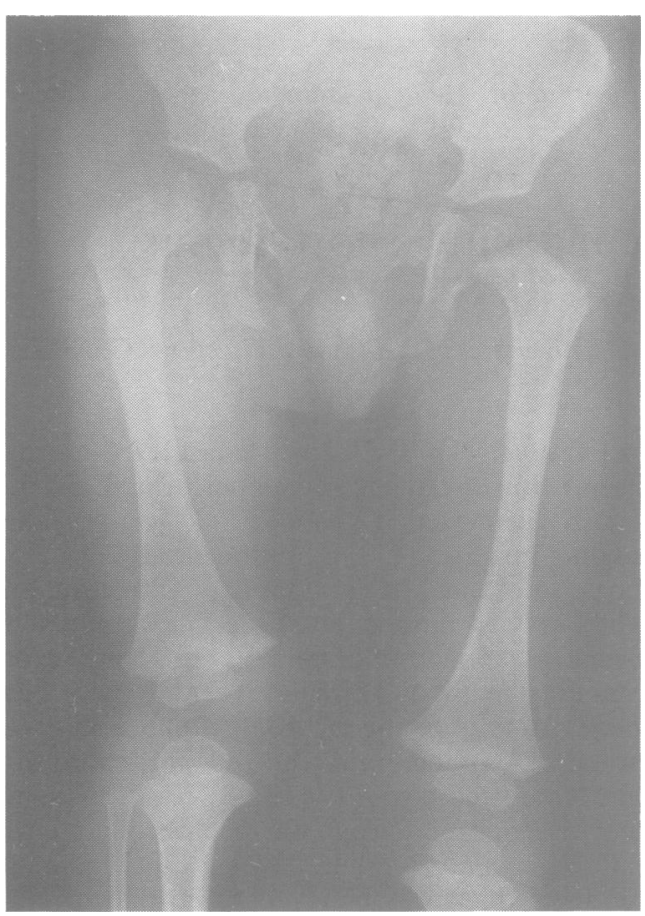

FIG 2 Twin 2 aged 17 months.

circumference of $58.5 \mathrm{~cm}$ and the absence of neurological findings. ${ }^{5}$

\section{Discussion}

With the present report there are now four instances of familial recurrence of congenital short femur. Ring $^{2}$ described a pair of concordant twins with congenital short femur in 1959 , but no comment was made about their zygosity. Kelly ${ }^{3}$ noted that a third degree relative had a curved femur, and in his comprehensive family study $\mathrm{Hamanishi}^{4}$ found only one familial recurrence in first cousins among $56 \bar{s}$ families studied. In this study, ${ }^{4}$ no raised parentato ages were found and only one set of parents waso consanguineous. Furthermore, three sets of discor- $\overline{-\bar{s}}$ dant twins of uncertain zygosity have been $\mathbb{\Omega}$ reported. ${ }^{46}$

With the exception of thalidomide, which is usually associated with more severe femoral defects, $\vec{\circ}$ no consistent environmental factors have been $\overrightarrow{\vec{H}}$ identified. Unifactorial inheritance is most unlikely and the observed patterns of familial recurrence and ${ }_{3}$ twin concordance favour multifactorial inheritanceco for simple femoral hypoplasia.

We wish to thank the Wellcome Trust and the National Fund for Research into Crippling Diseases for financial support.

\section{References}

' Rogala EJ, Wynne-Davies R. Littlejohn A, Gormley J. Congenital limb anomalies: frequency and actiological factors. Data from the Edinburgh Register of the newborn (1964-1968).

J Med Genet 1974:11:221-33.

2 Ring PA. Congenital short femur. Simple femoral hypoplasia. $J^{\prime}$ Bone Joint Surg (Br) 1959:41:73-9.

${ }^{3}$ Kelly TE. Proximal focal femoral deficiency (familial). Birth Defects 1974:10(12):508-9.

+ Hamanishi C. Congenital short femur. Clinical, genetic and epidemiological comparison of the naturally occurring condition with that caused by thalidomide. J Bone Joint Surg $(B r) \unrhd$ 1980;62:307-20.

5 Asch AJ. Myers GJ. Benign familial macrocephaly. Report of a음 family and review of the literature. Pediatrics 1976;57:535-40.

6 Westin GW, Gunderson FO. Proximal femoral focal deficiency: a review of treatment experiences. In: Aitken GT, ed. Proximal femoral focal deficiency. A congenital anomaly. Symposium held in Washington, June 13, 1968. Washington: National Academy of Sciences, 1969:1-22.

Correspondence and requests for reprints to Dr J Me. Connor, Duncan Guthrie Institute of Medical Gene-尺्र tics, Yorkhill, Glasgow G3 8SJ.

\title{
Poland syndrome associated with 'morning glory' syndrome (coloboma of the optic disc)
}

\author{
D T PIŠTELJIĆ*, D VRANJEŠEVIC**,S APOSTOLSKI†, AND \\ D D PIŚTELJIC**
}

${ }^{*}$ Institute for Neurology and Psychiatry of Childhood and Adolescence, and +Clinic for Neurology, 11000 Belgrade, Yugoslavia.

SUMmary A 12 year old girl with the Poland syndrome and the 'morning glory' syndrome is described. The patient presented with absence

Received for publication 2 March 1985.

Revised version accepted for publication 4 July 1985. of the left pectoralis major muscle, hypoplasia ${ }^{\infty}$ of the left arm, symbrachydactyly, and ipsi- $\frac{0}{0}$ lateral coloboma of the optic disc. This is the요 first report of the association of these two congenital anomalies. 